\title{
Prevalence of schistosomiasis and associated factors among students attending at elementary schools in Amibera District, Ethiopia*
}

\author{
Worku Awoke $^{1 \#}$, Melkamu Bedimo ${ }^{1}$, Molalign Tarekegn ${ }^{2}$ \\ ${ }^{1}$ College of Medicine and Health Sciences, Bahir Dar University, Bahir Dar, Ethiopia; \\ \#Corresponding Author: workuawo@yahoo.com \\ ${ }^{2}$ GAMBY College of Medical Sciences, Bahir Dar, Ethiopia
}

Received 12 January 2013; revised 9 March 2013; accepted 13 April 2013

Copyright (C) 2013 Worku Awoke et al. This is an open access article distributed under the Creative Commons Attribution License, which permits unrestricted use, distribution, and reproduction in any medium, provided the original work is properly cited.

\begin{abstract}
Introduction: Schistosomiasis is one of the most prevalent parasitic diseases and an important public health problem in many developing countries including Ethiopia. The study was aimed at assessing prevalence of schistosomiasis and associated factors among students attending at elementary schools in Amibera District, Ethiopia. Methods: A cross sectional school based study was carried out on sample of $\mathbf{8 4 0}$ students. First, all elementary schools around Amibera District were grouped in to strata based on their distance from the irrigation site as "Near" or "Far". Then two schools were selected by simple random sampling method from each stratum. Finally, proportional allocation of the sample size was done according to the number of students in each stratum. From each grade level students were selected by simple random sampling techniques. A pre-tested structured questionnaire was used to collect data on socio demographic characteristics, water contact habit and toilet utilization. Stool and urine examination were done to determine prevalence. The analysis was carried out using SPSS version 16.0. Result and Conclusions: The overall prevalence of schistosomiasis in this study was $8.2 \%$; among this
\end{abstract}

\footnotetext{
Competing Interests: The authors declare that they have no competing interests.

Authors' contributions:

Worku Awoke was involved in proposal development, data cleaning, and data analysis and manuscript preparation.

Molalign Tarekegn was involved in proposal development, pre-testing the questionnaire, supervising the data collectors, data entry, analysis and manuscript preparation.

Melkamu Bedimo was involved in proposal development, data cleaning and data analysis and manuscript preparation.
}

Schisosoma haematobium was $7.4 \%$ and Schisosoma mansoni was $0.8 \%$. Education level ( $p$ value $=0.047$, OR $=1.834)$, swimming habit $(p-$ value $=0.0001, \mathrm{OR}=4.979$ ) and source of water for domestic consumption ( $p$-value $=0.0001$, OR $=0.334$ ) had shown significant association with the occurrence of $S$. haematobium infection. Conclusion and recommendations: The prevalence of schistosomiasis was not what to be neglected. It was significantly associated with educational level, swimming habit of children and source of water for domestic consumption. Therefore, provision of safe water supply and health education at school level was recommended.

Keywords: Prevalence; Schistosomiasis; Amibera District; Ethiopia

\section{INTRODUCTION}

Schistosomiasis is one of the most prevalent parasitic diseases and an important public health problem in many developing countries. Globally, schistosomiasis ranks second among parasitic diseases of socio-economic and public health importance and is found in 48 African countries [1]. An estimated 779 million people are at risk of schistosomiasis, of whom 106 million (13.6\%) live in irrigation schemes or in close proximity to large dam reservoirs and the majority of these infections occur in Sub-Saharan Africa [2,3].

The disease is mostly seen among the poor Sub-Saharan Africa. It was listed among the 13 diseases classified by World health organization as "Neglected Tropical diseases [4]. It is prevalent in tropical and sub-tropical areas, especially in poor communities that had low access to 
safe drinking water and adequate sanitation. It is estimated that at least $90 \%$ of those requiring treatment for schistosomiasis live in Africa [5].

The three main species infecting humans are Schisosoma haematobium (S. haematobium), Schisosoma japonicum (S. japonicum), and Schisosoma mansoni (S. manson). Two other species, more localized geographically, are Schisosoma mekongi and Schisosoma intercalatum. Schistosomiasis in Africa is caused by an infection with S. mansoni and S. haematobium whose eggs may be found in feces or urine respectively [6].

School-age children who live in areas with poor sanitation are often most at risk because they tend to spend time swimming or bathing in water containing infectious cercariae [7].

In Ethiopia, the prevalence of schistosomiasis infection varies from localities. Previous studies showed that the prevalence of $S$. mansoni among school children was $85 \%$ in Zarim, 67\% Gorgora [8], 5.95\% among school children of different water source users in Tigray [9], 67.6\% in Finchaa valley [10] and $20.6 \%$ among schooled children in Gorgora [11]. Hygiene and play habits make children especially vulnerable to infection [5].

This study was aimed at assessing prevalence of schistosomiasis and associated factors among students attending at elementary schools in Amibera Woreda, Ethiopia.

\section{METHODS}

\subsection{Study Design and Study Area}

A quantitative school based cross sectional study was carried out in Amibera District, Ethiopia. The district is found in Afar Regional State, located $270 \mathrm{~km}$ east of Addis Ababa .In the district there is one hospital, one health center and eight health stations. "Middle Awash irrigation Project" is also one irrigation project in the district. Concerning educational institutions there are 12 elementary, 3 high schools, and one technique school. There are 8670 number of students attending in 12 elementary schools. The total population of the study area is estimated to be 32,086 [12].

\subsection{Sample Size Determination}

The source population consisted of all students found in the 12 elementary schools. This study examined selected students from 4 elementary schools. The sample size was determined by using a single population proportion formula, which took the prevalence in the locality $54 \%$ with a margin of error of 0.05 at the $95 \%$ confidence interval (CI); then correction was made since the population was less than 10,000. Finally multiplying by a design effect of 2 and adding a 15\% non-response rate, the final sample size was calculated to be 840 students.

\subsection{Sampling Techniques}

All elementary schools were stratified based on distance from the irrigation site, as "Near" or "Far". Then two schools were selected by simple random sampling method from each stratum. Proportional allocation of the sample size was done according to the number of students in each stratum and grade level. Students were selected by simple random sampling techniques using list of students as a sampling frame. A pre tested structured questionnaire was used to collect data on socio demographic, water contact habit and toilet utilization. Stool and urine examination were done to determine prevalence. The analysis was carried out using SPSS version 16.0.

Specimens (stool and urine) were collected by data collectors on-the-spot into separate dry, clean and labeled cup and the stool was preserved in $10 \%$ formalin. The 828 stool samples were transported by the data collectors to the laboratory at "National Hospital" found in Amibera district and processed using formal ether concentration technique for microscopic examination. In order to ensure quality of the data; proper training was given for data collectors, pre-testing was done on $5 \%$ of the sample size and smears were examined independently by two experienced laboratory technologist and finally checked by the supervisor.

\subsection{Ethical Considerations}

The research topic and methodology were approved by the ethical committee of Bahir Dar University and GAMBY College of Medical Sciences. Ethical clearance was obtained from the Ethical Committee of GAMBY College of medical sciences and Bahir Dar University. Permission to conduct the study was also obtained from school directors. During data collection, the purpose of the study was clearly explained to students and informed oral consent was obtained and for those positives treatment was given

\subsection{Limitations}

Data like water contract habit, source of water for drinking and toilet utilization were based on responses of students to the structured questionnaire. It would be more informative if it was done at the household level to identify the actual household practices.

\section{RESULTS AND DISCUSSIONS}

\subsection{Socio-Demographic Characteristic of Study Subjects}

A total of 828 of school children were participated in this study making the response rate of $98.3 \%$. From this, $518(62.6 \%)$ were male, 581 (70.2\%) in the age group 
between 10 to 14 and 357 (43.1\%) were Muslims (Table 1).

\subsection{Water Contact Habit and Toilet Utilization}

In this study water contact habit and toilet utilization was assessed and the result shows that 294 (35.5\%) of students have a habit for swimming, 311(37.6\%) have a habit for washing clothes in the drainage, 243 (29.3\%) have a habit for cutting grass near by the drainage, 296 (35.7\%) have a habit of water contact during crossing and about 514 (62.1\%) students reported that they use latrine facilities for urination and defecation (Table 2).

\subsection{Prevalence of Schistosomiasis among Students}

Laboratory analysis was done for 828 stool and urine samples. The result shows that 68 (8.2\%) students were found to be infected by schistosomiasis. From the total positives, 61 (7.4\%) and $7(0.8 \%)$ of the students were infected by $S$. haematobium and $S$. mansoni respectively. Distribution of the parasite for both sexes showed that; $S$. haematobium was observed in 27 out of 310 females and 34 out of 518 males. The prevalence of $S$. mansoni was 5 $(0.6 \%)$ and $2(0.2 \%)$ for males and females respectively. Of the total 828 students with S. haematobium infection, $5(9.0 \%)$ students were in the age group 15 - 19 years, 49 $(8.43 \%)$ in 10 - 14 years and 3.4\% in 20 - 24 years. Moreover $9.7 \%$ and $4.5 \%$ of $S$. haematobium was observed among students attending within 1 - 4 and 5 - 8 grade

Table 1. Socio-demographic characteristics of students, Amibera district, Ethiopia March 2012 (n = 828).

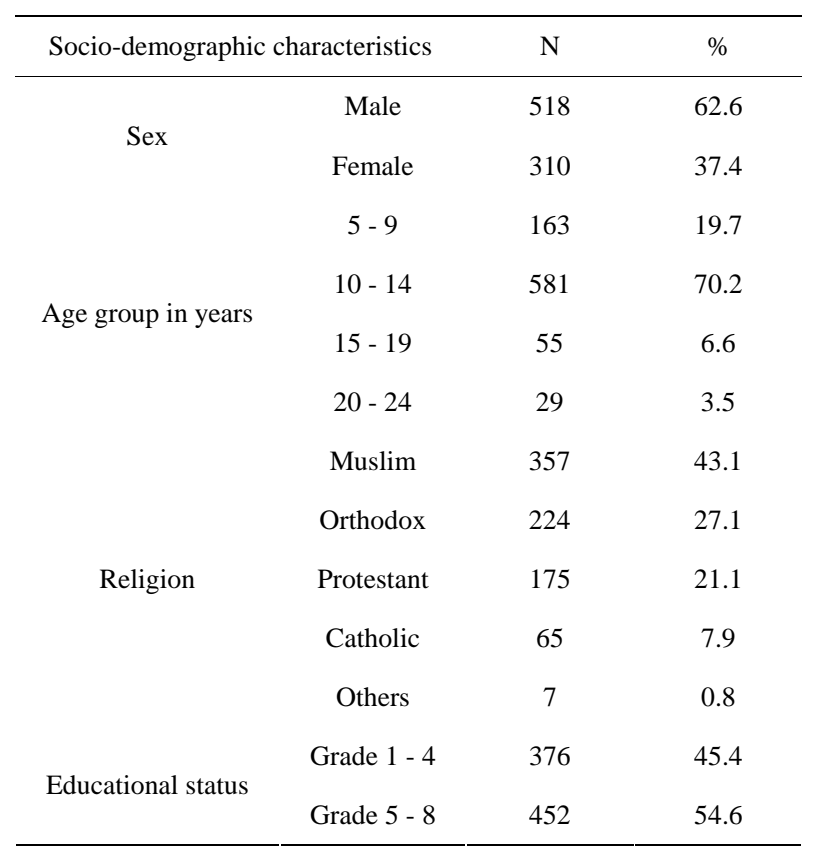

Table 2. Water contact habit and toilet utilization among students attending at elementary schools in Amibera Woreda, Ethiopia March 2012.

\begin{tabular}{|c|c|c|c|}
\hline \multicolumn{2}{|c|}{ Water contact habit and toilet utilization } & \multirow{2}{*}{$\frac{N}{294}$} & \multirow{2}{*}{$\begin{array}{c}\% \\
35.5\end{array}$} \\
\hline & Yes & & \\
\hline \multirow[t]{3}{*}{ Swimming habit } & No & 534 & 64.5 \\
\hline & Total & 828 & 100 \\
\hline & Yes & 243 & 29.3 \\
\hline \multirow[t]{3}{*}{ Cutting grass } & No & 585 & 70.7 \\
\hline & Total & 828 & 100 \\
\hline & No & 532 & 64.3 \\
\hline \multirow[t]{3}{*}{$\begin{array}{l}\text { Drainage contact } \\
\text { While crossing }\end{array}$} & Yes & 296 & 35.7 \\
\hline & Total & 828 & 100 \\
\hline & Yes & 311 & 37.6 \\
\hline \multirow[t]{3}{*}{$\begin{array}{l}\text { Washing cloths } \\
\text { in the drainage }\end{array}$} & No & 517 & 62.4 \\
\hline & Total & 828 & 100 \\
\hline & Tap/protected well & 707 & 85.4 \\
\hline \multirow[t]{3}{*}{$\begin{array}{l}\text { Source water } \\
\text { for domestic use }\end{array}$} & Drainage & 121 & 14.6 \\
\hline & Total & 828 & 100 \\
\hline & Yes & 514 & 62.1 \\
\hline \multirow[t]{2}{*}{ Toilet utilization } & No & 314 & 37.9 \\
\hline & Total & 828 & 100 \\
\hline
\end{tabular}

level respectively. The distribution of S. haematobium was also explored with regard to water contact habit and toilet utilization in detail. The result showed that 46 (75.4\%) of infected students had a habit of swimming, 25 (40.9\%) had a habit of washing their clothes in the drainage, 25 (40.9\%) uses drainage as domestic water source, $61(100 \%)$ had a habit of cutting grass in the nearby water sources, $29.5 \%$ crossing the drainage and $54.9 \%$ had a habit of open filled defecation (Table 3).

\subsection{Factors Associated with the Occurrence of S. haematobium}

\section{Results from Bivariate Analysis}

Bivariate analysis was carried out to examine factors associated with $S$. haematobium and p-value less than or equal to 0.2 was considered as cut off point for considering variables for entry in to multiple logistic regression. Accordingly, among the socio demographic factors Age ( $\mathrm{p}$-value $=0.187)$ and education level of students ( $\mathrm{p}$-value $=0.005$ ) showed significant association with $S$. haematobium. However sex and religion were not significantly associated with occurrence of S. haematobium (Table 4).

Among water contact habit, swimming ( $\mathrm{p}$-value = 
Table 3. Prevalence of Schisosoma haematobium with water contact habit and toilet utilization among students in Amibera District, Ethiopia March 2012.

\begin{tabular}{|c|c|c|}
\hline Variables & $\begin{array}{l}\text { Number of infected } \\
\text { students with } S \text {. } \\
\text { haematobium }\end{array}$ & Percent \\
\hline \multicolumn{3}{|l|}{ Swimming habit } \\
\hline Yes (294) & 46 & 75.4 \\
\hline No (534) & 15 & 24.6 \\
\hline Total (828) & 61 & 100 \\
\hline \multicolumn{3}{|l|}{ Washing clothes } \\
\hline Yes (311) & 25 & 40.9 \\
\hline No (517) & 36 & 59.1 \\
\hline Total (828) & 61 & 100 \\
\hline \multicolumn{3}{|l|}{ Water source for domestic use } \\
\hline Pipe/protected well (707) & 36 & 59.0 \\
\hline Drainage (121) & 25 & 61.0 \\
\hline Total (828) & 61 & 100 \\
\hline \multicolumn{3}{|l|}{ Cutting grass } \\
\hline Yes (243) & 61 & 100 \\
\hline No (585) & 0 & 0 \\
\hline Total (828) & 61 & 100 \\
\hline \multicolumn{3}{|l|}{$\begin{array}{l}\text { Water contact during crossing } \\
\text { the drainage }\end{array}$} \\
\hline Yes (296) & 18 & 29.5 \\
\hline No (532) & 43 & 30.5 \\
\hline Total (828) & 61 & 100 \\
\hline \multicolumn{3}{|l|}{ Toilet utilization } \\
\hline Yes (514) & 28 & 45.9 \\
\hline No (318) & 33 & 54.1 \\
\hline Total (828) & 61 & 100 \\
\hline
\end{tabular}

$0.0001)$, source of water for house domestic purpose $(p$-value $=0.0001)$ and toilet utilization $(p$-value $=0.008)$ showed significant association with $S$. haematobium. Cutting grass, drainage water contact during crossing and washing clothes were not significantly associated with occurrence of S. haematobium (Table 5).

\subsection{Results from Multivariate Analysis}

By considering the independent variables that become significant on the bivariate analysis; multiple binary logistic regression analysis was carried out to assess the adjusted or net effect of the independent variables. Students from grade level 1 to 4 were 1.997 times (95\% CI: 1.098, 3.633) more likely to be infected than those from grade level 5 to 8 . Those students who had a habit for swimming were 4.74 times (95\% CI: 2.524, 8.920) at a higher risk to be infected with $S$. haematobium. School childern from households using pipe/protected water were
0.345 times (95\% CI: $0.191,0.625)$ less likely to be infected than those children from household using the drainage as a domestic water source. Age and toilet utilization were not significantly associated with $S$. haematobium in multivariate analysis (Table 6).

\section{DISCUSSIONS}

This study was aimed at assessing prevalence of schistosomiasis and associated factors among students in elementary schools around "Middle Awash Irrigation Project”. The overall prevalence of schistosomiasis was found to be $8.2 \%$, the prevalence of $S$. haematobium and S. mansoni being $7.4 \%$ and $0.8 \%$ respectively. This study showed a lower prevalence rate of $S$. mansoni compared to the research findings reported in other areas of Ethiopia, $85 \%$ in Zarim, 67\% Gorgora [8], 67.6\% in Finchaa valley [10] and 20.6\% among schooled children in Gorgora [11]. This difference may be due to difference in water contact habit, toilet utilization and the low prevalence of vectors. The study area was known for its being low land and hot, however the snail responsible for the transmission of S. mansoni infection (Biomphalaria pfeifferi) is more prevalent in areas $2000 \mathrm{~m}$ above sea level and the optimal temperature for its development and survival is around $25^{\circ} \mathrm{C}$. Above $30^{\circ} \mathrm{C}$ snail mortality increases, as a result this may contribute for the low prevalence of the disease [13].

In the present study, schistosomiasis did not show a significant variation with sex, which was consistent with a research finding reported from Nigeria [14], however it was inconsistent with a research finding reported by others [11]. This may be due to the difference in the division of labor in different regions of the country. In some places mostly males were more involved in field work activities than females and in others, females are involved more in field work activities. In the place where this study was conducted males and females might have similar exposure for water contact and other field work activities. Age, education level, swimming habit and domestic water source of the household were significantly associated with risk of $S$. haematobium among school children.

\section{CONCLUSIONS}

In conclusion, the present study showed that Schistosomiasis was spreading as a result of the irrigation project run in the area. S. haematobium infection was found to be significantly associated with educational level of the students, swimming habit and source of water for domestic purpose. Therefore, the prevalence of Schistosoma in this area was not what to be neglected. Provision of safe water supply and since the most affected group were low level class students, provision of health education on schistosomiasis transmission and its method of prevention is 
Table 4. Distribution of S. haematobium infection with socio-demographic variables, among students attending at elementary schools in Amibera District, Ethiopia March 2012.

\begin{tabular}{|c|c|c|c|c|}
\hline \multirow{2}{*}{ Variables } & \multicolumn{2}{|c|}{ S. haematobium } & \multirow{2}{*}{ Crude OR (95.0\%C.I.) } & \multirow{2}{*}{ p-value } \\
\hline & Positive & Negative & & \\
\hline \multicolumn{5}{|l|}{ Sex } \\
\hline Male & 34 & 484 & $0.736(0.435,1.246)$ & 0.254 \\
\hline Female & 27 & 283 & 1.00 & \\
\hline \multicolumn{5}{|l|}{ Age in years } \\
\hline $5-9$ & 6 & 157 & 1.00 & 0.187 \\
\hline $10-14$ & 49 & 532 & $2.41(1.014,5.731)$ & 0.047 \\
\hline $15-19$ & 5 & 50 & $2.61(0.766,8.941)$ & 0.125 \\
\hline $20-24$ & 1 & 28 & $0.93(0.108,8.062)$ & 0.951 \\
\hline \multicolumn{5}{|l|}{ Religion } \\
\hline Orthodox & 10 & 214 & 1.00 & 0.320 \\
\hline Muslim & 24 & 333 & $1.542(0.723,3.289)$ & 0.262 \\
\hline Protestant & 17 & 158 & $2.303(1.027,5.164)$ & 0.043 \\
\hline Catholic & 3 & 62 & $1.035(0.276,3.879)$ & 0.959 \\
\hline Others & 7 & 0 & $3.45(0.00$ & 0.999 \\
\hline \multicolumn{5}{|c|}{ Educational level } \\
\hline $1-4$ & 44 & 408 & $2.27(1.278,4.057)$ & 0.005 \\
\hline $5-8$ & 17 & 359 & 1.00 & \\
\hline
\end{tabular}

Table 5. Association of S. haematobium with water contact habit and toilet utilization among students attending at elementary schools in Amibera District, Ethiopia March 2012.

\begin{tabular}{|c|c|c|c|c|c|}
\hline \multirow{2}{*}{\multicolumn{2}{|c|}{ Associated factors }} & \multicolumn{2}{|c|}{ S. haematobium } & \multirow{2}{*}{ Crude OR (95.0\% C.I.) } & \multirow{2}{*}{ p-value } \\
\hline & & \multirow{2}{*}{$\begin{array}{c}\text { Positive } \\
46 \\
15\end{array}$} & \multirow{2}{*}{$\begin{array}{c}\text { Negative } \\
248 \\
519\end{array}$} & & \\
\hline Swimming habit & $\begin{array}{l}\text { Yes } \\
\text { No }\end{array}$ & & & $\begin{array}{c}6.41(3.515,11.718) \\
1.00\end{array}$ & 0.0001 \\
\hline Water souce & $\begin{array}{c}\text { Tap } \\
\text { Drainage }\end{array}$ & $\begin{array}{l}36 \\
25\end{array}$ & $\begin{array}{c}671 \\
96\end{array}$ & $\begin{array}{c}0.206(0.118,0.358) \\
1.00\end{array}$ & 0.0001 \\
\hline Washing clothes & $\begin{array}{l}\text { Yes } \\
\text { No }\end{array}$ & $\begin{array}{l}25 \\
36\end{array}$ & $\begin{array}{l}286 \\
481\end{array}$ & $\begin{array}{c}1.16(0.87,1.986) \\
1.00\end{array}$ & 0.567 \\
\hline Water contact during crossing & $\begin{array}{l}\text { Yes } \\
\text { No }\end{array}$ & $\begin{array}{l}18 \\
43\end{array}$ & $\begin{array}{l}278 \\
489\end{array}$ & $\begin{array}{c}0.736(0.417,1.301) \\
1.00\end{array}$ & 0.292 \\
\hline Toilet utilization & $\begin{array}{l}\text { Yes } \\
\text { No }\end{array}$ & $\begin{array}{l}28 \\
33\end{array}$ & $\begin{array}{l}486 \\
281\end{array}$ & $\begin{array}{c}0.491(0.290,0.829) \\
1.00\end{array}$ & 0.008 \\
\hline
\end{tabular}

Table 6. Multivariate analysis of factors associated with S. haematobium among students attending at elementary schools in Amibera District, Ethiopia March 2012.

\begin{tabular}{|c|c|c|c|c|}
\hline \multirow{2}{*}{ Associated factors } & \multicolumn{2}{|c|}{ S. haematobium } & \multirow{2}{*}{ Crude OR (95.0\% C.I.) } & \multirow{2}{*}{ Adjusted OR (95.0\% C.I.) } \\
\hline & $(+)$ & $(-)$ & & \\
\hline \multicolumn{5}{|l|}{ Education level } \\
\hline $1-4$ & 44 & 408 & $2.27(1.278,4.057)$ & $1.997(1.098,3.633)$ \\
\hline $5-8$ & 17 & 359 & 1.00 & 1.00 \\
\hline $\begin{array}{c}\text { Swimming habit } \\
\text { Yes } \\
\text { No }\end{array}$ & $\begin{array}{l}46 \\
15\end{array}$ & $\begin{array}{l}248 \\
519\end{array}$ & $\begin{array}{c}6.41(3.515,11.718) \\
1.00\end{array}$ & $\begin{array}{c}4.745(2.524,8.920) \\
1.00\end{array}$ \\
\hline \multicolumn{5}{|l|}{ Water source } \\
\hline Tap & 36 & 671 & $0.206(0.118,0.358)$ & $0.345(0.191,0.625)$ \\
\hline Drainage & 25 & 96 & 1.00 & 1.00 \\
\hline
\end{tabular}


highly recommended at school level.

\section{ACKNOWLEDGEMENTS}

We would like to thank Bahir Dar University and GAMBY College of Medical Sciences. We are also grateful for the cooperation of the schools directors and study participants

\section{REFERENCES}

[1] WHO (1999). Report of the WHO informal consultation of schistosomiasis control. WHO/CDS/SIP/99.2, WHO, Geneva.

[2] Touré, S., Zhang, Y., Bosqué-Oliva, E., Ky, C., Ouedraogo, A., Koukounari, A., Gabrielli, A.F., Sellin, B., Webster, J.P. and Fenwick, A. (2008) Two-year impact of single praziquantel treatment on infection in the national control programme on schistosomiasis in Burkina Faso. Bulletin of the World Health Organization, 86, 780-787.

[3] Steinmann, P., Keiser, J., Bos, R., Tanner, M. and Utzinge, J. (2006) Schistosomiasis and water resources development: systematic review, meta-analysis, and estimates of people at risk. Lancet Infect Disease, 6, 411-425. doi:10.1016/S1473-3099(06)70521-7

[4] Hotez, P.J., Molyneux, D.H., Fenwick, A., et al. (2007) Control of neglected tropical diseases. The New England Journal of Medicine, 357, 1018-1027. doi:10.1056/NEJMra064142

[5] WHO (2012). Schistosomiasis. http://www.who.int/mediacentre/factsheets/fs115/en/inde x.html

[6] CDC (2012) Parasite and health: Schistosomiasis. http://www.dpd.cdc.gov/dpdx/HTML/Schistosomiasis.htm
[7] CDC (2012). Parasite: Schistosomiasis. http://www.cdc.gov/parasites/schistosomiasis/

[8] Moges, T., Mesganaw, F., Afework, K., Gebeyaw, T., Van Lieshout, L. and Polderman, A.M. (2001) Schistosomiasis mansoni in school attenders and non-attenders in Northwest Ethiopia. Ethiopian Journal of Health Development, 15, 117-123.

[9] Dejenie, T. and Asmelash, T. (2010) Schistosomiasis mansoni among school children of different water source users in Tigray, Northern Ethiopia. Momona Ethiopian Journal of Science, 2, 49-60. doi:10.4314/mejs.v2i1.49650

[10] Haile, S., Golassa, L. and Mekonnen, Z. (2012) Prevalence of Schistosoma mansoni and effectiveness of Praziquantel in school children in Finchaa valley, Ethiopia. Journal of Parasitology and Vector Biology, 4, 25-30.

[11] Essa, T., Birhane, Y., Endris, M., Moges, A. and Moges, F. (2013) Current status of Schistosoma mansoni infections and associated risk factors among student in Gorgora town, Northwest Ethiopia. ISRN Infectious Diseases, 2013, Article ID 630103.

[12] CSA (Central Statistical Agency of Ethiopia) (2008) Summary and statistical report of the 2007 population and housing census. CSA (Central Statistical Agency of Ethiopia), Addis Ababa.

[13] Brooker, S. (2007) Spatial epidemiology of human schistosomiasis in Africa: Risk models, transmission dynamics and control. Transactions of the Royal Society of Tropical Medicine and Hygiene, 101, 1-8. doi:10.1016/j.trstmh.2006.08.004

[14] Ekpo, U.F., Laja-Deile, A., Oluwole, A.S., et al. (2010) Urinary schistosomiasis among preschool children in a rural community near Abeokuta, Nigeria. Parasites \& Vectors, 3, 58.

\section{LIST OF ABBREVIATIONS}

AOR: Adjusted Odds Ratio

CI: Confidence Interval

OR: Odds Ratio

$\mathrm{Km}$ : Kilometers

SPSS: Statistical Package for Social Sciences 